\title{
El cromoglicato inhalatorio no fue efectivo en niños de 1 a 4 años con asma moderada
}

Randomised placebo-controlled trial of inhaled sodium cromoglycate in 1-4 years old children with moderate asthma. Tasche M, Van Der Wouden J, Uijen J, et al. Lancet 1997; 350:1060-4

\section{Objetivo}

Evaluar efectos terapéuticos, adherencia y factibilidad del tratamiento con cromoglicato inhalatorio con aerocámara y adaptador facial.

\section{Diseño}

Ensayo clínico, randomizado, doble ciego, controlado con placebo. Seguimiento a 5 meses.

\section{Lugar}

Consultorios externos de Medicina General y Pediatría de 3 hospitales en Rotterdam, Holanda.

\section{Pacientes}

Se incluyeron 218 niños de 1a 4 años con asma moderada definida como 12 o más episodios de disnea, tos o sibilancias que hubieran requerido medicación antiasmática en el último año y/o por lo menos 2 de los siguientes criterios en el último mes: 1 o más episodios disnea, tos o sibilancias por semana; síntomas respiratorios que interfirieran la actividad diaria; síntomas respiratorios que interfirieran el sueño.

\section{Intervención}

Se randomizaron 109 pacientes al grupo cromoglicato y 109 al grupo placebo. Luego de un periodo de lavado, los pacientes podían utilizar aparte de la medicación del estudio la asociación de ipratropio más fenoterol como medicación de rescate. Se educó a los padres de los pacientes en la técnica de administración de fármacos con aerocámara más adaptador facial y se pidió que registraran en forma diaria una escala sintomática, medicación de rescate utilizada, efectos adversos, consultas al médico de cabecera y guardia.

\section{Medición de resultados}

Días libres de síntomas. Resultados secundarios: $\mathrm{N}^{\mathrm{O}}$ de síntomas, medicación de rescate, visitas al medico de cabecera y especialistas, medicación adicional antiasmática.

\section{Resultados}

El análisis fue por intención de tratar*. El 77\% de los pacientes completaron el estudio, la causa más común de abandono fue dificultad en la técnica de administración. Estos fueron los resultados principales:

\begin{tabular}{|l|c|c|}
\hline Eventos & Cromoglicato $(\mathrm{n}=109)$ & Placebo $(\mathrm{n}=109)$ \\
\hline $\begin{array}{l}\text { \% de días libres } \\
\text { de síntomas } \pm \text { IC 95\% }\end{array}$ & $65.7(61.1-70.3)$ & $64.3(59.7-68.9)$ \\
\hline $\begin{array}{l}\text { Tos después } \\
\text { de inhalación }\end{array}$ & $8 \%$ & $1 \%(\mathrm{p} 0.02)$ \\
\hline $\begin{array}{l}\text { Eccema peribucal } \\
\text { y nasal }\end{array}$ & $5 \%$ & $0 \%(\mathrm{p} \mathrm{0.052)}$ \\
\hline
\end{tabular}

No hubo diferencias clínicas ni estadísticas con respecto al promedio de días libres de síntomas entre los grupos (IC 95\% de la diferencia -8.21 a 6.41). Hubo aumento de efectos adversos me nores en el grupo cromoglicato. No se halló diferencias en los resultados secundarios.

\section{Conclusiones}

Si bien es factible la administración de cromoglicato con aerocámara y adaptador facial a pacientes asmáticos moderados de 1 a 4 años de edad, no hay diferencias terapéuticas con respecto al placebo.

Fuente de financiamiento: Netherlands Asthma Foudation

\section{Comentario}

El manejo del asma cambió desde que comenzó a tratarse como una enfermedad inflamatoria. Hay trabajos que muestran que tratar el componente inflamatorio con corticoides inhalatorios disminuye la tasa de hospitalización, el número de crisis, el uso de medicación de rescate y mejora los parámetros espirométricos (1). El efecto del cromoglicato como droga antiinflamatoria es controvertido: algunos trabajos muestran beneficios y otros no. La mayoría de estos trabajos fueron en pacientes internados con asma severa o con tiempo de seguimiento menor a 10 semanas(2-3). Las guías de tratamiento del asma en niños recomiendan tratar con drogas broncodilatadoras de acción corta a demanda a los pacientes con asma leve. En pacientes con asma moderada y severa se debe agregar una droga antiinflamatoria. La droga antiinflamatoria de primera elección recomendada en niños es el cromoglicato y si luego de 2 meses de uso no se logra controlar al paciente se debe reemplazar por corticoides inhalatorios. Se recomienda agregar b2 adrenérgicos de acción prolongada si con dosis de 400 a $800 \mathrm{mg} / \mathrm{día}$ de beclometasona no se logra estabilizar al paciente (4). Hay controversias en la literatura sobre los efectos adversos de los corticoides inhalatorios en relación al crecimiento estatural. Hay trabajos que muestran alteraciones en el progreso estatural en relación a la dosis de corticoides aún con los corticoides más modernos (budesonida, fluticaso- na)(5-6). Un meta-análisis de 21 trabajos prospectivos no encontró alteraciones de la altura aún utilizando altas dosis de corticoides inhalatorios (7). Es muy importante el aporte que hacen estos dos trabajos al manejo del asma de los niños. El de Tasche y cols. aporta importante evidencia para replantearse el lugar del cromoglicato en el control del asma. A los fines de concluir con la controversia hubiese sido importante la evaluación del cromoglicato administrabít por nebulización para evaluar los efectios ant esta vía de administración. El trabajo áte mons y cols destaca que si bien los cana coides inhalatorios son útiles aún pan = $=$ nejo del asma leve, éstos tienen éfenara versos sobre la estatura del paciente l 